\title{
Penurunan Konsentrasi Anion Fosfat dan Sulfat dalam Air Limbah Hasil Proses Pengolahan Senotim dengan Metode Elektrokoagulasi
}

\section{Decreased Concentrations of Anion Phosphate and Sulphate in Wastewater of Xenotime Treatment Process Results using Electrocoagulation method}

\author{
Kharistya Rozana*, Devi Swasti Prabasiwi, dan Dewi Puspa Ariany \\ Pusat Sains dan Teknologi Akselerator Badan Tenaga Nuklir Nasional, Jl. Babarsari Kotak Pos 6101 Depok, Sleman, \\ 55281, Indonesia
}

\section{Artikel histori :}

Diterima 3 September 2020 Diterima dalam revisi 29 Oktober 2020 Diterima 30 Oktober 2020 Online 31 Oktober 2020

\begin{abstract}
ABSTRAK: Indonesia memiliki sumber daya mineral logam tanah jarang yang berpotensi untuk diolah menjadi produk yang bermanfaat untuk kehidupan manusia dan bernilai ekonomis tinggi. Di dalam pengolahan sumber daya mineral logam tanah jarang diperlukan perangkat pengolahan limbah untuk mereduksi kontaminan dalam limbah cair hasil proses, perangkat pengolahan limbah dikembangkan sesuai kebutuhan teknis berdasarkan aspek teknologi dan biaya. Proses pengolahan limbah cair di lingkungan industri kimia saat ini selain masih terpaku pada teknologi yang tersedia, dan membutuhkan bahan kimia pendukung proses pengolahan dengan biaya tinggi. Metode pengolahan dengan sistem elektrokoagulator digunakan karena teknologi elektrokoagulasi tidak membutuhkan tingkat teknologi dan biaya tinggi. Pada penelitian ini dilakukan pengolahan air limbah hasil proses senotim dengan menggunakan metode elektrokoagulasi dengan variasi tegangan dan waktu kontak. Dijesti pasir senotim menggunakan asam sulfat pekat dan di dalam kandungan pasir senotim terdapat anion fosfat yang berikatan dengan logam Y, Dy, Gd, La, Ce, Nd. Proses pengolahan limbah senotim dengan metode elektrokoagulasi diatur pada variasi tegangan 7V-13V dengan waktu 0-120 menit. Hasil analisis dengan HPLC menunjukkan adanya penurunan kadar anion fosfat dan sulfat di dalam filtrat hasil pengolahan limbah senotim dengan menggunakan metode elektrokoagulasi. Konsentrasi anion fosfat dan sulfat terendah terjadi pada kondisi tegangan $13 \mathrm{~V}$ dengan waktu 120 menit yaitu $1,18 \%$ dan $0,564 \%$ dari konsentrasi anion fosfat dan sulfat mula-mula $11,469 \%$ dan $0,991 \%$
\end{abstract}

Kata Kunci: elektrokoagulasi; variasi tegangan dan waktu kontak; air limbah hasil proses senotim; anion fosfat dan sulfat

ABSTRACT: Indonesia has rare earth mineral resources that have the potential to be processed into beneficial products for human life. In the processing of rare earth mineral resources rarely needed waste treatment devices to reduce contaminants in liquid waste process results. The method of processing with the electrocoagulator system is used because its does not require high levels of technology and costs. In research conducted wastewater treatment process results of xenotime by using method of electrocoagulation with variation of voltage and time of contact. Digestion of xenotime sand using concentrated sulfuric acid and in the content of xenotime sand there is a phosphate anion that binds with metal Y, Dy, Gd, $\mathrm{La}, \mathrm{Ce}, \mathrm{Nd}$. Xenotime wastewater treatment process with electrocoagulation method is set at voltage variation $7 \mathrm{~V}-13 \mathrm{~V}$ with variation time of $0-120$ minutes. The results of analysis with High Performance Liquid Chromatography (HPLC) showed that there is a decrease in the concentration of phosphate and sulfate anions in the filtrate of the processing results of xenotime wastewater using electrocoagulation method. The lowest concentrations of phosphate and sulfate anions occur in the $13 \mathrm{~V}$ voltage condition with 120 minutes of $1.180 \%$ and $0.564 \%$.

Keywords: electrocoagulation; variation of voltage and time of contact; xenotime wastewater treatment process; HPLC; phosphate and sulfate anions

\section{Pendahuluan}

"Corresponding Author: +62 812-1810-1845

Email: kharistya.rozana@batan.go.id
Pasir senotim pada umumnya ditulis dengan rumus molekul $\mathrm{LTJPO}_{4}$ atau $\mathrm{YPO}_{4}$ merupakan salah satu mineral 
yang mengandung logam tanah jarang yaitu Itrium (Y), Gadolinium (Gd), Disprosium (Dy), Lanthanum (La), Cerium (Ce), Neodimium $(\mathrm{Nd})$. Kandungan unsur pasir senotim yang paling banyak digunakan adalah itrium sedangkan unsur-unsur lainnya relatif kecil. Salah satu cara untuk mendapatkan konsentrat itrium (Y) dari pasir senotim dengan proses dijesti menggunakan asam sulfat kemudian dilakukan proses pengendapan dengan hidroksida. Proses dijesti ini bertujuan untuk memecah dan melarutkan sehingga unsur-unsur dalam logam tanah jarang dapat terlarut (Handini et al., 2018). Logam-logam di dalam pasir senotim ini merupakan logam yang mempunyai nilai ekonomis yang tinggi, mempunyai kegunaan yang sangat luas, karena secara umum memiliki kekuatan mekanis yang baik, titik leleh relatif tinggi, dan memiliki sifat-sifat yang sangat menguntungkan sehingga dimanfaatkan dalam berbagai bidang industri. Dy memiliki luas penampang serap neutron yang tinggi sehingga cocok digunakan sebagai batang kendali reaksi fisi untuk reaktor nuklir. Selain itu disprosium juga memiliki sifat magnetis dan termal yang ideal untuk digunakan sebagai bagian dari berbagai macam produk modern yang memerlukan magnet permanen, seperti generator turbin angin, motor kendaraan elektrik, hard disk, MRI, dan sistem audio. Gadolinium oksida nanopartikel merupakan bahan potensial yang dapat dimanfaatkan sebagai agen kontras pada Magnetic Resonance Imaging (MRI). Gd juga dipergunakan secara luas pada industri tenaga nuklir. Perusahaan General Electric menggunakan gadolinium oksida pada boiling water reactors (BWRs) sebagai burnable portion, yang dicampur langsung dengan uranium oksida untuk mencapai fluks neutron yang seragam sepanjang umur elemen bahan bakar. Gd juga digunakan sebagai penyerap neutron termal (Jordens et al., 2013).

Limbah hasil proses pengolahan dijesti pasir senotim mengandung anion fosfat dan sulfat. Proses elektrokoagulasi dapat menurunkan kandungan anion-anion yang terdapat dalam larutan setelah mengalami proses koagulasi karena munculnya pengendapan (Setianingrum, Prasetya, dan Sarto, 2016). Pengolahan anion fosfat dan sulfat menjadi perhatian penting dalam penelitian ini karena anion-anion essensial seperti halnya fosfat dan sulfat merupakan salah satu parameter yang digunakan untuk meninjau penurunan kualitas air (Muldawati, 2017).

Laksmi, et. al (2013) telah melakukan pengolahan air untuk menghilangkan anion nitrat dengan metode elektrokoagulasi menggunakan plat $\mathrm{Al}$ sebagai anoda dan $\mathrm{Ph}$ air 7,00 dan daya listrik yang dialirkan sebesar 6,26 kWh diperoleh efisiensi penurunan kadar anion nitrat dalam air yaitu 95,9\%. Mithra, et. al (2017) telah melakukan pengolahan air untuk menghilangkan anion fosfat dengan metode elektrokoagulasi menggunakan plat $\mathrm{Al}$ dengan dialiri tegangan $10 \mathrm{~V}$ diperoleh efisiensi penurunan kadar anion fosfat dalam air yaitu 98\%. Hashim, et. al (2019) telah melakukan proses elektrokoagulasi untuk menghilangkan kandungan anion fosfat di dalam air sungai, dengan konsentrasi anion fosfat awal 100 ppm diperoleh efisiensi penurunan anion fosfat yaitu 99\% pada pengaturan $\mathrm{pH} 6$ dan waktu elektrolisis selama 60 menit. Penurunan kadar anion fosfat dan sulfat dalam air limbah proses dijesti pasir senotim pada penelitian ini dilakukan dengan proses elektrokoagulasi menggunakan elektroda aluminium sebagai anoda yang disusun secara paralel dalam reaktor batch dan dihubungkan dengan arus DC dialiri tegangan 7 , 10, dan $13 \mathrm{~V}$.

Elektroda disusun paralel sehingga arus dibagi diantara semua elektroda dan tegangan yang dibutuhkan lebih rendah dibandingkan rangkaian seri. Prinsip dasar proses ini adalah reaksi oksidasi dan reduksi (redoks). Pada elektroda anoda terjadi peristiwa oksidasi, sedangkan pada katoda terjadi reaksi reduksi (Saputra dan Hanum, 2016). Energi listrik akan mengalir melalui katoda menuju anoda sehingga pada katoda menjadi bermuatan negatif dan ion-ion logam yang berada pada larutan elektrolit akan ditarik pada katoda. Anoda berfungsi sebagai koagulan dalam proses koagulasiflokulasi proses tersebut, dan katoda akan menghasilkan gelembung-gelembung gas hidrogen yang berfungsi menaikkan flok-flok yang tersuspensi (Wiyanto et al., 2014). Mekanisme pada proses elektrokoagulasi ada beberapa diantaranya perpindahan dan penetralan, kation atau ion hidroksil $\left(\mathrm{OH}^{-}\right)$yang dihasilkan akan mengendap dengan polutan. Proses reaksi oksidasi pada anoda akan mengakibatkan larutnya logam alumunium menjadi ion $\mathrm{Al}^{3+}$, yang akan mengalami reaksi hidrolisis menghasilkan $\mathrm{Al}(\mathrm{OH})_{3}$ berbentuk padatan yang tidak dapat larut dalam air yang berfungsi sebagai koagulan. Selanjutnya koagulan akan mengikat kontaminan-kontaminan dalam limbah cair yang diolah (Nasrullah et al., 2016). Interaksi logam dengan $\mathrm{OH}^{-}$dalam bentuk hidroksida yang mana mempunyai kemampuan adsorbsi yang tinggi dalam mengikat polutan dalam limbah (bridge coagulation). Reaksi sebagai berikut: Reaksi pada anoda

$$
\begin{aligned}
& \mathrm{Al}_{(\mathrm{s})} \longrightarrow \mathrm{Al}^{3+}{ }_{(\mathrm{aq})}+3 \mathrm{e}^{-} \\
& \mathrm{Al}^{3+}{ }_{(\mathrm{aq})}+3 \mathrm{OH}^{-}{ }_{(\mathrm{aq})} \longrightarrow \mathrm{Al}(\mathrm{OH})_{3(\mathrm{~s})}
\end{aligned}
$$

Reaksi pada katoda

$$
3 \mathrm{H}_{2} \mathrm{O}_{(\mathrm{l})}+3 \mathrm{e}^{-} \longrightarrow 1,5 \mathrm{H}_{2(\mathrm{~g})}+3 \mathrm{OH}_{(\mathrm{aq})}^{-}
$$

Reaksi Keseluruhan

$$
\mathrm{Al}_{(\mathrm{s})}+3 \mathrm{H}_{2} \mathrm{O}_{(\mathrm{l})} \longrightarrow \mathrm{Al}(\mathrm{OH})_{3(\mathrm{~s})}+1,5 \mathrm{H}_{2(\mathrm{~g})}
$$

Dengan adanya gas $\mathrm{H}_{2}$ yang dihasilkan membuat ion hidroksida yang mengikat polutan dalam limbah menjadi senyawa yang tidak larut yang akan mengalami pengapungan ke permukaaan reaktor atau disebut juga flotasi (Ridantami et al., 2016). Kandungan anion-anion fosfat dan sulfat di dalam hasil olah pasir senotim sebelum dan setelah proses elektrokoagulasi dapat dianalisis dengan menggunakan HPLC. Baku mutu kandungan lepasan anion fosfat dan sulfat kelas IV (air yang dapat digunakan untuk mengairi pertanaman) berdasarkan Peraturan Pemerintah No. 82 Tahun 2001 yaitu $5 \mathrm{ppm}$ dan $0,2 \mathrm{ppm}$. Anion fosfat di dalam air tanah yang dapat diserap untuk pertumbuhan tanaman hanya berkisar $0,92-1,53 \mathrm{mg} / \mathrm{kg}$ dari berat tanaman, sedangkan anion sulfat di dalam air tanah dapat mengakibatkan reaksi penyerapan fosfat pada tanaman menjadi lebih lambat (Sumbahan, 2012). Tujuan penelitian ini yaitu untuk mengetahui kondisi optimum proses elektrokoagulasi air limbah hasil pengolahan pasir senotim untuk menurunkan kandungan anion-anion fosfat dan sulfat 
dengan melakukan variasi tegangan dan waktu kontak. Harapan dengan menentukan kondisi optimum proses elektrokoagulasi skala laboratorium ini nantinya dapat dikembangkan sebagai parameter data awal dalam pengembangan metode elektrokoagulasi sebagai pengolahan limbah cair yang dihasilkan oleh laboratorium proses PSTABATAN.

\section{Metode Penelitian}

Peralatan yang digunakan dalam penelitian ini yaitu neraca analitik, spatula, pipet volume $10 \mathrm{~mL}$, propipet, 6 buah pelat alumunium, reaktor elektrokoagulasi, amperemeter, voltmeter, $\mathrm{pH}$ meter, kertas saring, pengaduk magnet, dan seperangkat instrument HPLC merk Waters.

Bahan yang digunakan dalam penelitian ini yaitu eluen natrium borat glukonat: butanol: asetonitril 1:1:2, $\mathrm{KH}_{2} \mathrm{PO}_{4}$, $\mathrm{Na}_{2} \mathrm{SO}_{4}$, limbah hasil proses senotim dan akuademin.

Tahapan proses penelitian yang dilakukan terbagi atas 2 proses yaitu proses elektrokoagulasi limbah proses pasir senotim dan proses analisis anion-anion pada sampel limbah proses senotim sebelum dan sesudah dilakukan proses elektrokoagulasi dengan menggunakan instrumen HPLC. Tahapan proses yang dilakukan dideskripsikan sebagai berikut:

\subsection{Proses elektrokoagulasi air limbah pengolahan proses dijesti pasir senotim}

Limbah proses senotim sebanyak $500 \mathrm{~mL}$ dimasukkan ke dalam reaktor elektrokoagulasi, kemudian dimasukkan 6 plat aluminium dan dirangkai dengan menggunakan kabel jack yang dihubungkan dengan voltmeter dan amperemeter. Proses elektrokoagulasi dilakukan pada variasi pengaturan tegangan $7 \mathrm{~V}, 10 \mathrm{~V}$, dan $13 \mathrm{~V}$ dengan pengambilan filtrat limbah proses dijesti senotim pada waktu kontak $0,10,20$, 30, 40, 50, 60, 70, 80, 90, 100, 110, dan 120 menit.

\subsection{Proses analisis anion-anion pada sampel air limbah pengolahan proses dijesti senotim sebelum dan sesudah elektrokoagulasi}

Sampel air limbah dari proses pengolahan dijesti pasir senotim sebelum dan sesudah elektrokoagulasi masingmasing variasi tegangan dan waktu kontak disaring dengan menggunakan syringe yang dilengkapi dengan filter ukuran pori $0,45 \mu \mathrm{m}$. Dilakukan injeksi larutan standar campuran anion sulfat dan fosfat dengan rentang konsentrasi $2 ; 4 ; 6 ; 8$; dan $10 \mathrm{ppm}$. Sampel diencerkan hingga 1000x untuk penentuan kadar anion sulfat dan diencerkan hingga 20.000x untuk penentuan kadar anion fosfat. Dilakukan injeksi larutan sampel dan ditentukan kadar masing anion fosfat dan sulfat dengan metode regresi linear.

\section{Hasil dan Pembahasan}

Air limbah yang dihasilkan dari proses dijesti pasir senotim diolah dengan proses elektrokoagulasi untuk menurunkan kandungan anion-anion fosfat dan sulfat yang dihasilkan dari proses dijesti pasir senotim dengan asam sulfat, pengendapan, dan ekstraksi.

Hasil analisis larutan kurva kalibrasi standar anion sulfat dan fosfat (Tabel 1) kemudian diekstrapolasikan dalam grafik kurva regresi linear yang disajikan pada Gambar 2 dan 3. Dari kurva regresi línear anion fosfat dan sulfat diperoleh nilai $\mathrm{R}^{2}$ masing-masing yaitu 0,9996 dan 0,992 serta diperoleh persamaan regresi linear $(y=m x+b)$ yang dapat digunakan untuk perhitungan konsentrasi anion fosfat dan sulfat di dalam sampel.

Tabel 1. Perhitungan Luas Area Puncak Anion

\begin{tabular}{ccc}
\hline \multirow{2}{*}{$\begin{array}{c}\text { Konsentrasi } \\
\text { larutan standar } \\
(\mathrm{ppm})\end{array}$} & \multicolumn{2}{c}{$\mathrm{L}$ area $\left(\mathrm{cm}^{2}\right)$} \\
\cline { 2 - 3 } & $\mathrm{PO}_{4}{ }^{3-}$ & $\mathrm{SO}_{4}{ }^{2-}$ \\
\hline 2 & 0,9 & 3,355 \\
4 & 1,755 & 4,84 \\
6 & 2,52 & 6,6 \\
8 & 3,33 & 8,25 \\
10 & 4,14 & 9,79 \\
\hline
\end{tabular}

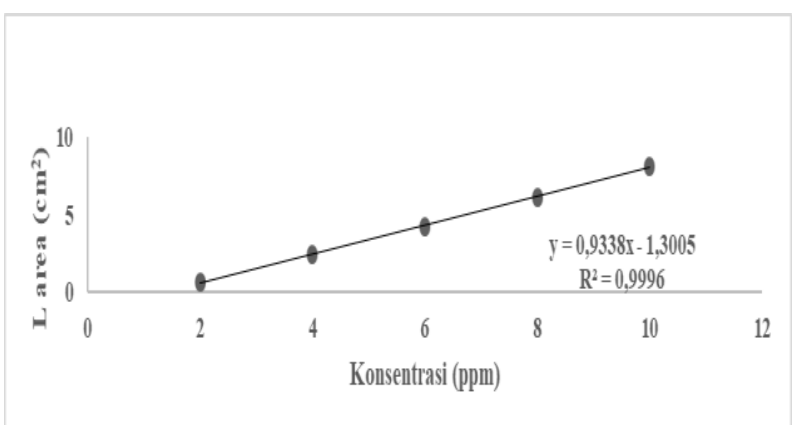

Gambar 2. Regresi Linear Larutan Standar Fosfat

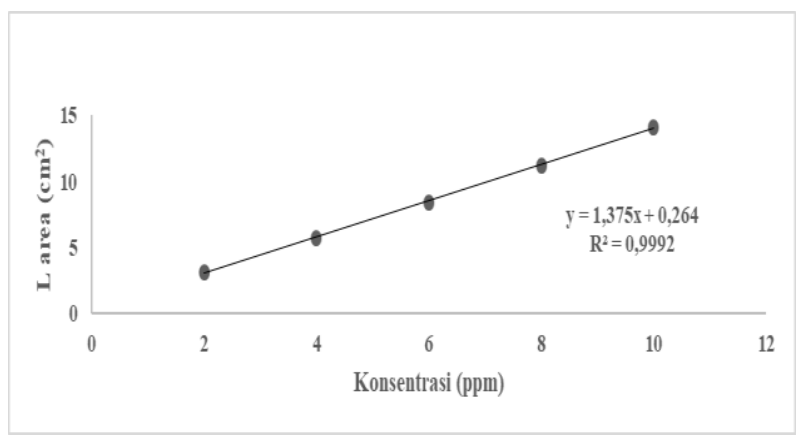

Gambar 3. Regresi Linear Larutan Standar Sulfat

Dari hasil perhitungan masing-masing persamaan regresi linear untuk penentuan kandungan anion fosfat dan sulfat maka diperoleh kandungan fosfat dan sulfat awal di dalam sampel limbah proses dijesti pasir senotim yang disajikan pada Tabel 2.

Setelah diketahui kandungan anion awal yang terkandung di dalam air limbah senotim, selanjutnya dilakukan proses pengolahan air limbah dengan metode elektrokoagulasi. Variasi yang digunakan dalam penelitian ini yaitu penggunaan tegangan dan waktu kontak elektrokogulasi. 
Proses sampling filtrat dilakukan pada bagian tengah reaktor elektrokoagulasi sebanyak $10 \mathrm{~mL}$ dengan menggunakan pipet ukur. Hasil filtrat ditampung ke dalam botol polietilen untuk dilakukan tahap preparasi sampel sebelum dilakukan analisis pengukuran kandungan anion fosfat dan sulfat.

Tabel 2. Kandungan Anion Fosfat dan Sulfat pada Air Limbah Proses Dijesti Senotim

\begin{tabular}{cccc}
\hline Anion & $\begin{array}{c}\mathrm{L} \text { area } \\
\left(\mathrm{cm}^{2}\right)\end{array}$ & $\begin{array}{c}\text { Kadar } \\
(\%)\end{array}$ & $\begin{array}{c}\text { Kadar } \\
\text { Rerata }(\%)\end{array}$ \\
\hline Fosfat & 11,275 & 11,784 & 11,469 \\
& 10,763 & 11,154 & \\
Sulfat & 0,900 & 0,978 & 0,991 \\
& 0,923 & 1,005 & \\
\hline
\end{tabular}

Proses preparasi analisis sampel hasil pengolahan dengan metode elektrokoagulasi dilakukan dengan cara menyaring sampel dengan menggunakan kertas saring ukuran pori $0,45 \mu \mathrm{m}$ dan diencerkan pada pengenceran 20.000x. Larutan sampel yang telah diencerkan kemudian diinjeksikan pada port syringe HPLC untuk dilakukan analisis kandungan anion fosfat.

Data kandungan anion fosfat pada digambarkan dalam bentuk grafik penurunan konsentrasi anion fosfat variasi tegangan dan waktu kontak yang disajikan pada Gambar 4. Dari grafik yang disajikan dapat diketahui bahwa semakin lama waktu kontak elektrokoagulasi yang dilakukan, maka anion fosfat yang terkandung di dalam filtrat semakin menurun. Penurunan anion fosfat terjadinya karena adanya proses pengendapan yang terjadi akibat reaksi antara plat $\mathrm{Al}$ dengan anion fosfat terlarut yang membentuk $\mathrm{AlPO}_{4}$. Konsentrasi anion fosfat pada pengolahan limbah senotim berkurang seiring dengan kenaikan tegangan elektrokoagulasi. Adanya aliran listrik yang mengalir dari katoda ke anoda sehingga Al pada plat alumunium akan lebih mudah teroksidasi dan berinteraksi dengan anion $\mathrm{PO}_{4}{ }^{3-}$ sehingga menghasilkan lebih banyak endapan $\mathrm{AlPO}_{4}$. Semakin banyak endapan $\mathrm{AlPO}_{4}$ yang dihasilkan, maka kandungan anion fosfat terlarut akan semakin menurun. Konsentrasi anion fosfat berkurang secara signifikan pada waktu kontak 120 menit untuk variasi tegangan 7, 10, dan $13 \mathrm{~V}$ berturut-turut yaitu 5,280\%; 1,680\%; dan 1,180\% dari konsentrasi anion fosfat awal pada limbah senotim yaitu $11,469 \%$. Efisiensi penurunan konsentrasi anion fosfat dengan metode elektrokoagulasi pada variasi tegangan 7, 10, dan $13 \mathrm{~V}$ yaitu 53,963\%; 85,352\%; dan 89,711\%.

Pengukuran kandungan anion sulfat dengan menggunakan HPLC diawali dengan melakukan preparasi sampel hasil pengolahan dengan metode elektrokoagulasi. Preparasi sampel dilakukan dengan cara menyaring sampel dengan menggunakan kertas saring ukuran pori $0,45 \mu \mathrm{m}$ dan diencerkan pada pengenceran 1.000x. Larutan sampel yang telah diencerkan kemudian diinjeksikan pada port syringe HPLC untuk dilakukan analisis kandungan anion sulfat.

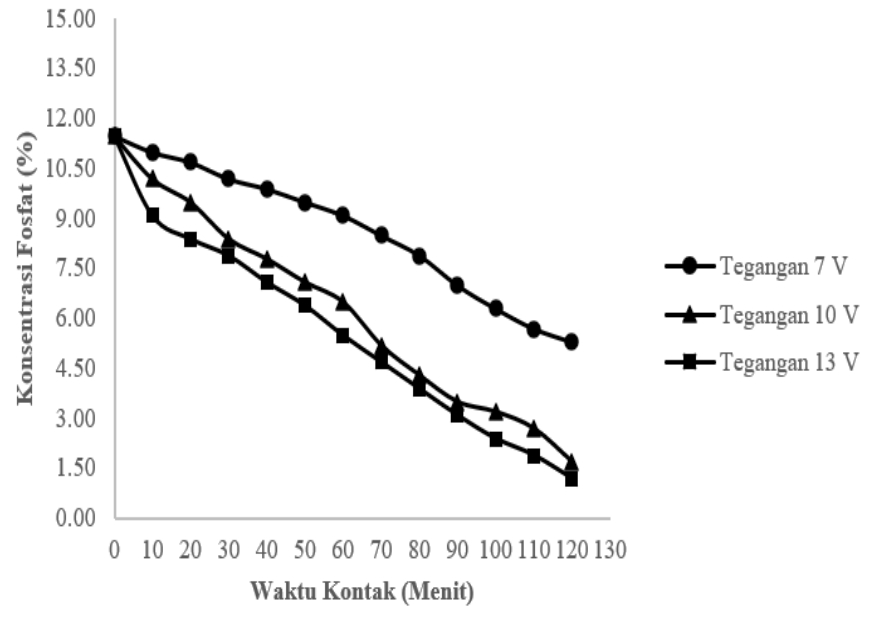

Gambar 4. Penurunan Kadar Anion Fosfat Hasil Elektrokoagulasi Variasi Tegangan

Data kandungan anion sulfat hasil elektrokoagulasi variasi tegangan digambarkan dalam bentuk grafik penurunan konsentrasi anion sulfat variasi tegangan dan waktu kontak yang disajikan pada Gambar 5. Dari grafik yang disajikan dapat diketahui bahwa semakin lama waktu kontak elektrokoagulasi yang dilakukan, maka anion sulfat yang terkandung di dalam filtrat semakin menurun. Penurunan anion sulfat terjadinya karena adanya proses pengendapan yang terjadi akibat reaksi antara plat $\mathrm{Al}$ dengan anion sulfat terlarut yang membentuk $\mathrm{Al}_{2}\left(\mathrm{SO}_{4}\right)_{3}$. Konsentrasi anion sulfat pada pengolahan limbah senotim berkurang seiring dengan kenaikan tegangan elektrokoagulasi. Adanya aliran listrik yang mengalir dari katoda ke anoda sehingga $\mathrm{Al}$ pada plat alumunium akan lebih mudah teroksidasi dan berinteraksi dengan anion $\mathrm{SO}_{4}{ }^{2-}$ sehingga menghasilkan lebih banyak endapan $\mathrm{Al}_{2}\left(\mathrm{SO}_{4}\right)_{3}$. Semakin banyak endapan $\mathrm{Al}_{2}\left(\mathrm{SO}_{4}\right)_{3}$ yang dihasilkan, maka kandungan anion sulfat terlarut akan semakin menurun. Konsentrasi anion sulfat berkurang secara signifikan pada waktu kontak 120 menit untuk variasi tegangan 7, 10, dan $13 \mathrm{~V}$ berturut-turut yaitu $0,703 \%$; $0,621 \%$; dan $0,564 \%$ dari konsentrasi anion sulfat awal pada limbah senotim yaitu $0,991 \%$. Efisiensi penurunan konsentrasi anion sulfat dengan metode elektrokoagulasi pada variasi tegangan 7,10 , dan $13 \mathrm{~V}$ yaitu $29,602 \%$; 37,336\%; dan $43,088 \%$. Efisiensi penurunan anion sulfat dengan metode elektrokoagulasi lebih rendah dibandingkan dengan anion fosfat, hal ini dikarenakan endapan koagulan $\mathrm{Al}_{2}\left(\mathrm{SO}_{4}\right)_{3}$ yang kurang stabil. Kelarutan $\mathrm{Al}_{2}\left(\mathrm{SO}_{4}\right)_{3}$ di dalam air sangat tinggi sehingga menyebabkan pengendapan anion sulfat dengan menggunakan plat $\mathrm{Al}$ menjadi kurang efisien. 


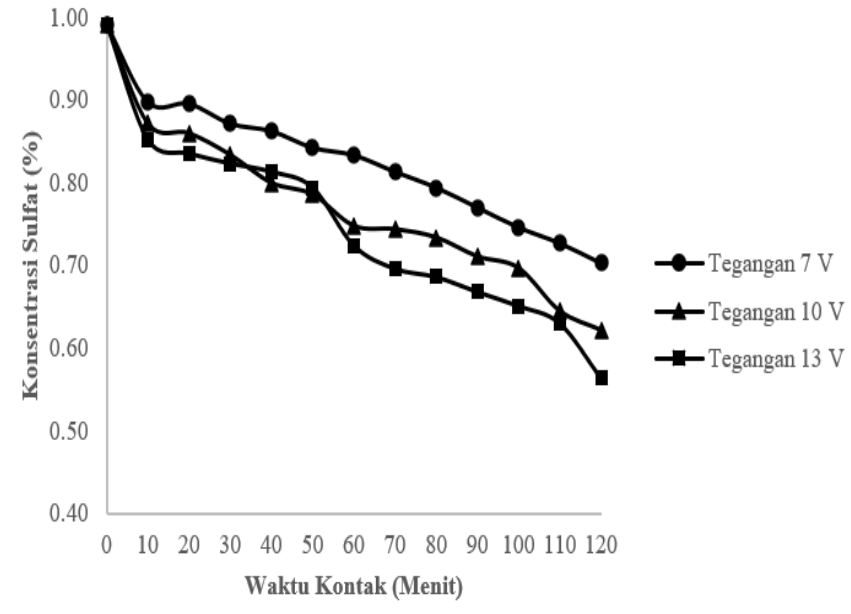

Gambar 5. Penurunan Kadar Anion Fosfat Hasil Elektrokoagulasi Variasi Tegangan

\section{Kesimpulan}

Proses pengolahan air limbah hasil proses dijesti pasir senotim dengan metode elektrokoagulasi variasi tegangan 7 , 10, dan 13 V serta waktu kontak 0, 10, 20, 30, 40, 50, 60, 70, $80,90,100,110$, dan 120 menit telah dilakukan dan dengan menggunakan analisis menggunakan HPLC menunjukkan adanya penurunan kadar anion fosfat dan sulfat seiring kenaikan tegangan dan waktu kontak. Kondisi optimum pengolahan air limbah hasil proses senotim ditinjau dari konsentrasi anion fosfat dan sulfat terendah yaitu pada kondisi tegangan $13 \mathrm{~V}$ dengan waktu kontak 120 menit yaitu $1,18 \%$ dan $0,564 \%$ dari konsentrasi anion fosfat dan sulfat awal $11,469 \%$ dan $0,991 \%$.

\section{Ucapan Terima kasih}

Penulis mengucapkan terima kasih kepada Instansi melalui anggaran DIPA 2019 PSTA BATAN sehingga penelitian ini dapat terlaksana. Penulis juga mengucapkan terima kasih atas bantuan rekan Wahyu Rachmi Pusparini, M.Eng, Triyono, ST dan Harry Supriadi, S.ST.

\section{Daftar Pustaka}

Handini, T., Rachmi, W., Supriadi, H., 2018, Pembuatan Konsentrat Itrium sebagai Umpan Ekstraksi. Prosiding Pertemuan \& Presentasi Ilmiah Penelitian Dasar Ilmu Pengetahuan \& Teknologi Nuklir ISSN 0216-3128, hlm. 157-160.

Hashim, K. S., et. al., 2019, Electrocoagulation as a Green Technology for Phosphate Removal from River Water, Journal of Separation and Purification Technology Vol. 210: 135-144.

Jordens, A., Cheng, Y. P., Waters, K. E. A., 2013, Review of the Beneficiation of Rare Earth Element Bearing Minerals, Minerals Engineering Vol. 41: 97-114.
Laksmi, J., Sozhan, G., Vasudevan, S., 2013, Recovery of Hydrogen and Removal Nitrate from Water by Electrocoagulation Process, Environment Science and Pollution Research Article Vol. 20: 2184-2192.

Mithra, S. S., Ramesh, S. T, Gandhimathi, R, Nidheesh, P. V., Studies on the Removal of Phosphate from Water by Electrocoagulation with Aluminium Plate Electrodes, Journal of Environmental Engineering Management Vol. 16: 2293-2302

Muldawati., 2017, Analisis Kandungan Anion Sulfat $\left(\mathrm{SO}_{4}{ }^{2-}\right)$, Nitrat $\left(\mathrm{NO}_{3}{ }^{-}\right)$, dan Fosfat $\left(\mathrm{PO}_{4}{ }^{3-}\right)$ dalam Sampel Air Muara Batang Arau Kota Padang. Skripsi Fakultas MIPA: Universitas Andalas.

Nashrullah, F. K., Hidayat, M., Fahrurrozi, M., 2016, Integrasi proses elektrokoagulasi-elektrooksidasi sebagai alternatif dalam pengolahan limbah cair batik zat warna naftol. Jurnal Rekayasa Proses Vol. 10 No.1: 3035 .

Ridantami, V., Wasito, V., Prayitno., 2016, Pengaruh tegangan dan waktu pada pengolahan limbah radioaktif uranium dan torium dengan proses elektrokoagulasi, Jurnal Forum Nuklir Vol. 10 No. 2: 102-107.

Saputra, E., Hanum, F., 2016, Pengaruh jarak antara elektroda pada reaktor elektrokoagulasi terhadap pengolahan efluent limbah cair pabrik kelapa sawit, Jurnal Teknik Kimia USU Vol. 5 No. 4: 33-38.

Setianingrum, N., P., Prasetya, A., Sarto, S., 2016, Pengaruh tegangan dan jarak antar elektroda terhadap pewarna remazol red $R B$ dengan metode elektrokoagulasi, Jurnal Inovasi Teknik Kimia Vol. 1 No. 2: 93-97.

Sumbahan, N., 2012, Pengaruh Asidulasi Batuan Fosfat dengan Pelarut Berupa Limbah Cair Industri Sawit dan Asam serta Lama Inkubasi terhadap Fosfat Larut, Skripsi Fakultas Pertanian, Universitas Lampung.

Wiyanto, E., Harsono, B., Makmur, A., Pangputra, R., Julita, J., Kurniawan, M. S., 2014, Penerapan elektrokoagulasi dalam proses penjernihan limbah cair, JETri Vol. 12 No.1: 19-36. 